\title{
Factors influencing Bachelor of Nursing Science students' attitude towards clinical exposure
}

\author{
M I Ofili, ${ }^{1} \mathrm{PhD} ;$ B P Ncama, ${ }^{1} \mathrm{PhD} ;$ O D Moses-Ewhre, ${ }^{2} \mathrm{BNSc}$ \\ ${ }^{1}$ School of Nursing and Public Health, College of Health Sciences, University of KwaZulu-Natal, Durban, South Africa \\ ${ }^{2}$ Department of Nursing Science, College of Health Sciences, Delta State University, Abraka, Nigeria
}

Corresponding author: I Ofili (isiomamary74@gmail.com)

\begin{abstract}
Background. Clinical exposure is an important component of the nursing curriculum aimed at engaging student nurses in learning and developing essential skills. Studies on students' attitude to clinical exposure have been conducted in Nigeria, but none in Delta State.

Objectives. To evaluate student nurses' attitude to and identify factors that influence their attitude to clinical exposure at Delta State University, Abraka, Nigeria. Methods. A descriptive quantitative design was used to elicit information from a sample of 181 individuals: 31 males and 150 females statistically drawn using a stratified sampling technique from a population of 237 at levels 300, 400 and 500 of study. A post hoc test was done to evaluate student nurses' attitude to clinical exposure at different levels of study.

Results. Results showed that $88 \%$ of respondents had a positive attitude towards clinical exposure. Post hoc tests indicated that attitude towards clinical exposure among 300- and 500-level students was statistically different ( $p=0.001$ ). Factors such as adequate clinical equipment, adequate supervision and guidance from clinical supervisors, behaviour of staff nurses in the ward and readiness to learn were the most frequently reported factors that influenced their attitude to clinical exposure. Fisher's exact test showed no association between these factors and respondents' attitude to clinical exposure ( $p=0.369$ ). Conclusion. Students' attitude to clinical exposure was positive, with average scores higher among 500-level students. Hence, the higher the level of study, the more positive their attitude was towards clinical exposure. Intensive preparation of nursing students before clinical training will help to improve their attitude.
\end{abstract}

Afr J Health Professions Educ 2019;11(4):145-148. https://doi.org/10.7196/AJHPE.2019.v11i4.1155

Nurses are important members of the healthcare team and constitute the largest group of healthcare providers globally. ${ }^{[1]}$ Nursing as a discipline deals with theory and practice. One of the key components of a nursing programme is the clinical experience component, also known as clinical exposure. It is an important component of the curriculum aimed at actively engaging student nurses in learning and developing essential skills. This usually takes place in clinical learning environments such as hospitals, school clinics, healthcare centres and other healthcare settings used for student learning.

Studies have shown that in the clinical setting, where theory is put into practice, the focus is on psychomotor activities (e.g. giving a patient a bed bath and medication), whereas cognitive abilities receive more focus in the classroom. ${ }^{[2]}$ Effective learning takes place when student nurses apply their classroom learning in the clinical setting - hence the need for clinical exposure. From an educational perspective, in the clinical learning environment setting, skills, knowledge and attitudes are developed, whereas in the theoretical part of the curriculum, these are applied, developed and integrated. ${ }^{[3]}$

Clinical experience is important for nursing education in a number of ways, such as preparing student nurses to perform clinical functions in practice, as well as knowing about these functions. The integration of theory and practice enables student nurses to learn effectively, feel confident regarding their skills and become competent in taking care of patients. ${ }^{[3]}$ As part of the academic preparation for the nursing profession, students are required to participate in clinical rotation work in various healthcare settings under the supervision of staff nurses at the facilities and clinical instructors from the educational institution. Studies have shown that clinical exposure helps student nurses to participate actively in the healthcare setting, seek solutions to real-life problems, and learn by doing while caring for patients. ${ }^{[4]}$ Attitude plays a major role in guiding human behaviour towards achievement of goals, awareness of consequences and effective processing of complex information regarding the learning environment. ${ }^{[5]}$ An important part of working with undergraduate nursing students is therefore building a positive attitude to clinical exposure as a vital component of their training. Attitude to clinical exposure can crucially influence nursing skills and competence once the student nurse graduates and cares for hospital patients. This study was aimed at evaluating student nurses' attitude to clinical exposure and identifying factors that influence their attitude to such exposure at Delta State University, Abraka, Nigeria.

\section{Methods}

\section{Study area and population}

Delta State University has three campuses, i.e. Oleh, Asaba and Abraka, and seven faculties (Law and Engineering at Oleh campus; Agriculture at Asaba campus, and Art, Science, Education and the College of Health Sciences at Abraka campus). Abraka campus has three sites (I, II and III). The College of Health Sciences is located at site III and has two faculties: Basic Medical Science and Clinical Science. The Faculty of Basic Medical Science comprises nursing science, anatomy, physiology, pharmacology and medical biochemistry, with a population of about 4500 students. The total population of nursing science students (2015/2016 session) is shown in Table 1. 


\section{Study design, sampling method and sample size}

A descriptive quantitative design was used. The Department of Nursing Science was purposively selected. Sample size was determined using Yamane's formula for quantitative study: $\mathrm{n}_{\mathrm{y}}=\mathrm{N} /\left(1+\mathrm{Ne}^{2}\right)$. The population of nursing students in the department was 237 (levels 300 - 500). A stratified sampling technique was used in selecting the participants at three levels of study (levels 300, 400 and 500). Stratified sampling was employed by dividing the entire population of nursing students into different strata/ subgroups: subgroup 1 - level 300, subgroup 2 - level 400 and subgroup 3 - level 500. Then, the final subjects were randomly selected proportionally from the different strata. After the stratified sampling technique, which ensured that the three clinical classes of nursing students were represented in the study, a simple random sampling technique was used to select 62 nursing students from year 5; 51 students from year 4; and 68 students from year 3, because of the larger number in that class. A total of 181 students constituted the sample size for this study. The clinical experience was only for students at these levels of study.

\section{Study procedures}

A questionnaire was used for data collection. It comprised three sections: sections $\mathrm{A}$ and $\mathrm{B}$ were self-constructed, while section $\mathrm{C}$ was adapted from Dlama et al. ${ }^{[6]}$ in their study on perception of nursing students and preceptors regarding factors influencing the clinical performance of nursing students. The instrument from Dlama et al. ${ }^{[6]}$ consists of 16 questions (related to our work). All the questions were used in the pilot study. In the main work, 13 questions were used after modification. The reasons for modification were to enable the researchers to achieve the study objectives, to exclude questions that were irrelevant and those that had the same responses. The first section consisted of questions regarding the respondents' sociodemographic data and other background information. The second section evaluated their attitude to clinical exposure, while the last section identified factors influencing their attitude to clinical exposure. The validity of the questionnaire was established by the use of content validity, and participants easily identified the variables described. The content validity was developed based on the analysis of each item for clarity, coverage, consistency and relevance. Items that were considered ambiguous were either rephrased or eliminated. The instrument (questionnaire) was pilot tested by administering it to 20 respondents. Cronbach's reliability was computed to ensure internal consistency of the instrument. An alpha value of $0.79(p<0.05)$ was obtained, which was an indication of good reliability. The participants gave written informed consent before data collection. The questionnaire was distributed to selected nursing students in their lecture areas, and was collected on the same day - after completion.

\section{Ethical approval}

The Delta State University Research and Ethical Committee granted ethical approval for this study (ref. no. REC/FBMS/DELSU/16/22). Participants were protected from any forms of harm by giving them information about the nature of the study/research, and participation was voluntary. Furthermore, their responses were treated confidentially and they were free to withdraw from the study at any time, without negative or undesirable consequences. A written informed consent form was signed by the participants. Anonymity and privacy were maintained by excluding all personal details from the final report and eliminating any cross-references that could link the results of the questionnaire to the participant. No identities were disclosed in journal articles published from the research. Confidentiality was also clearly spelled out in the questionnaire. All data files were saved as password-protected documents.

\section{Data analysis}

Data were processed and analysed using SPSS version 25 (IBM Corp, USA), and summary data were presented using descriptive statistics (frequency distribution and percentages) and inferential statistics. Fisher's exact test was conducted to establish the association between respondents' attitude to clinical exposure and factors influencing their attitude to clinical exposure.

\section{Results}

A summary of the characteristics of the study participants $(n=181)$ is given below. Participants were fairly evenly distributed between the three levels of study - from level 300 to level 500 , with slightly more $(37.5 \% ; n=68)$ from level 300 and slightly fewer $(28.2 \% ; n=51)$ from level 400 . The age range of respondents was between 20 and 38 years, with a mean of 24.64 (2.36) years. With regard to age distribution, $69.1 \%(n=125)$ of respondents were in the 23 - 27-year age bracket, $20.4 \%(n=37)$ in the 18 - 22-year bracket, $8.8 \%(n=16)$ in the 28 - 32-year bracket, and only 3 were $\geq 33$ years of age. There was a majority of female participants $(82.9 \% ; n=150)$, a majority of single participants $(88.4 \% ; n=160)$, and all but 3 were Christians $(91.7 \%$; $n=177)$. Roughly a third of participants $(34.8 \% ; n=63)$ were from the Igbo ethnic group. With regard to mode of entry to the university, the majority (82.9\%; $n=150)$ of participants gained admission through the University Matriculation Examination (UME).

Table 2 presents the frequency distribution of respondents' attitude to clinical exposure. Respondent scores on the attitude-to-clinical-exposure scale were measured at two levels: positive (strongly agree and agree) with a score of $\geq 4$, and negative (strongly disagree, disagree and uncertain), with a score $<4$. Of the 181 respondents, $88.4 \%(n=160)$ scored $>4$ (positive) and $11.6 \%(n=21)$ scored $<4$ (negative). Scores ranged from 1 to 7 , with a mean of 4.53 (0.97). On evaluation of attitude towards clinical exposure, $88.4 \%$ $(n=160)$ had a positive attitude, while $11.6 \%(n=21)$ had a negative attitude.

Table 1. Population of nursing science students (2015/2016)

\begin{tabular}{ll}
\hline Level of study & Students, $\boldsymbol{n}$ \\
\hline 100 & 66 \\
200 & 64 \\
300 & 82 \\
400 & 81 \\
500 & 73 \\
\hline
\end{tabular}

Total 366

Table 2. Frequency distribution of respondents' attitude to clinical exposure

\begin{tabular}{ll}
\hline Attitude & Frequency (\%) \\
\hline Positive & $160(88.4)$ \\
Negative & $21(11.6)$ \\
Total & $181(100)$
\end{tabular}


A one-way analysis of variance (ANOVA) test of student nurses' attitude to clinical exposure by their levels of study is set out in Table 3. Seven attitudinal questions were asked and students were given a total score out of 7, which was converted to a percentage. Students' attitude was scored as follows: $1=$ positive and $0=$ negative. Using a one-way ANOVA, average student scores were compared among 300-, 400- and 500-level students with the following scores: $78.6 \%, 87.1 \%$ and $92.3 \%$, respectively. These scores were found to be statistically different $(p=0.001)$. Because of the statistically significant one-way ANOVA, a post hoc test was conducted to ascertain the differences in their attitude towards clinical exposure at the different levels of study. The test indicated that attitude towards clinical exposure among 300 - and 500-level students was statistically different $(p=0.001)$. However, attitude towards clinical exposure among 300- and 400-level students, as well as 400 - and 500-level students, was not statistically different $(p=0.080$ and $p=0.410$, respectively).

Table 4 presents the frequency distribution of factors that influenced respondents' attitude to clinical exposure. Respondent scores were measured at two levels: high $\geq 7$, and low $<7$. Of the 181 respondents, $93.9 \%(n=170)$ scored $>7$ (high reported factor values) and 6.1\% $(n=11)$ scored $<7$ (low

Table 3. One-way analysis of variance (ANOVA) test of student nurses' attitude to clinical exposure by level of study

\begin{tabular}{llll}
\hline Level of study & $\begin{array}{l}\text { Attitude towards clinical } \\
\text { exposure, mean }\end{array}$ & $\boldsymbol{f}$-test & $\boldsymbol{p}$-value \\
\hline 300 & 78.6 & 6.838 & 0.001 \\
400 & 87.1 & & \\
500 & 92.3 & & \\
& & &
\end{tabular}

Table 4. Frequency distribution of factors influencing respondents' attitude to clinical exposure

\begin{tabular}{ll}
\hline Factor values & Frequency (\%) \\
\hline High values & $170(93.8)$ \\
Low values & $11(6.1)$ \\
Total & $181(100)$
\end{tabular}

reported factor values). Scores ranged from 2 to 13 , with a mean of 10.56 (2.07)

Table 5 shows the reported factors influencing respondents' attitude to clinical exposure. The factors most frequently reported were adequate clinical equipment $(94.5 \% ; n=171)$, adequate supervision and guidance from clinical supervisors $(94.5 \% ; n=171)$, behaviour of practising/staff nurses in the ward $(93.9 \% ; n=170)$, regularity $(93.4 \% ; n=169)$ and readiness to learn (91.7\%; $n=166)$.

Table 6 presents contingency findings showing respondents' attitude to clinical exposure and the identified factors influencing their attitude to clinical exposure. The null hypothesis showed that there was no association between respondents' attitude to clinical exposure and identified factors influencing their attitude to clinical exposure. Using Fisher's exact test, it was ascertained that there was no association between students' attitude to clinical exposure and factors influencing their attitude to clinical exposure $(p=0.369)$.

\section{Discussion}

Most of the respondents were young adults. Marital status showed that $88.4 \%(n=160)$ were single and $11.6 \%(n=21)$ were married. Therefore, the majority of respondents were not subject to marital obligations. The majority $(n=150)$ of participants were female, re-emphasising the general belief that the nursing profession continues to be female dominated.

An understanding of students' perception and attitude during clinical exposure and training can assist in the effective evaluation of the strengths and weaknesses of an educational programme, thus promoting curricular development in support of holistic nursing care. Previous studies ${ }^{[7-9]}$ found that among student nurses the clinical learning environment is perceived as the most influential context for gaining nursing skills and knowledge.

In evaluation of attitude towards clinical exposure, $88.4 \%(n=160)$ had a positive attitude and $11.6 \%(n=21)$ had a negative attitude. In line with previous research, ${ }^{[10-12]}$ this study also showed that nursing students had a positive attitude towards clinical experience and that clinical practice and available opportunities provided a reflection of the process of becoming a professional nurse. This is contrary to Awuah-Peasah et al. $\mathrm{s}^{[5]}$ finding that nursing students had a negative attitude towards clinical exposure. This was

Table 5. Distribution of responses to factors influencing attitude to clinical exposure

\begin{tabular}{lll}
\hline Factors & High values, $\boldsymbol{n}$ (\%) & Low values, $\boldsymbol{n}$ (\%) \\
\hline Institutional & & $11(6.1)$ \\
Behaviour of practising/staff nurses in the ward & $170(93.9)$ & $10(5.5)$ \\
Adequate clinical equipment & $171(94.5)$ & $21(11.6)$ \\
Duration of clinical time & $160(88.4)$ & $10(5.5)$ \\
Adequate supervision and guidance from clinical supervisors & $171(94.5)$ & $33(18.2)$ \\
Feedback from clinical supervisors & $148(81.8)$ & $19(10.5)$ \\
Integration of theory into practice & $162(89.5)$ & $62(34.3)$ \\
Selecting staff nurses for their roles & $119(65.7)$ & $25(13.8)$ \\
Preparing staff nurses for their roles & $156(86.2)$ & $38(21.0)$ \\
Individual & & $15(8.3)$ \\
Anxiety & $143(79.0)$ & $48(26.5)$ \\
Readiness to learn & $166(91.7)$ & $12(6.6)$ \\
Active participation during ward rounds & $133(73.8)$ & $27(14.9)$ \\
Regularity & $169(93.4)$ &
\end{tabular}


Table 6. Relationship between identified factors and respondents' attitude to clinical exposure

\begin{tabular}{|c|c|c|c|}
\hline \multirow[b]{2}{*}{ Factor values } & \multicolumn{2}{|c|}{$\begin{array}{l}\text { Attitude to clinical } \\
\text { exposure, } n(\%)\end{array}$} & \multirow[b]{2}{*}{$p$-value (Fisher's exact test) } \\
\hline & Positive & Negative & \\
\hline & & & 0.369 \\
\hline High values & $151(93.8)$ & $11(6.2)$ & \\
\hline Low values & $17(89.5)$ & $2(10.5)$ & \\
\hline
\end{tabular}

apparently seen in their behaviour during clinical training, which included nursing students reporting late for work, being absent from clinical work without permission, using mobile phones during clinical working hours and lacking commitment to clinical work. A previous study ${ }^{[13]}$ also reported that nursing students had a negative attitude towards clinical exposure. This was seen in their behaviour during clinical postings at hospitals, which included anxiety, feelings of vulnerability, lack of respect and loss of interest. Nursing students also identified the following factors as influencing their attitude towards clinical exposure: adequate clinical equipment, adequate supervision and guidance from clinical supervisors, behaviour of practising staff nurses in the ward, duration of clinical time, integration of theory into practice, selecting and preparing staff nurses for their roles, anxiety, regularity and readiness to learn. Other important factors that previous studies have identified as influencing nursing students' attitude to clinical exposure (either positively or negatively) are: preceptorship and mentorship, good relationship with nurses, clinical supervision, professional role acceptance, simulation, peer teaching and learning, high levels of stress and anxiety, poor interpersonal relationships, theory-practice gap, inadequate clinical time, overcrowded clinical facilities, shortage of equipment and staff and lack of feedback. ${ }^{[6,9,14,15]}$ Factors at an academic level that have been similarly identified are programme of study, ineffective communication, inadequate preparation and emotional reactions. ${ }^{[16,17]}$ Fisher's exact test indicated no significant association between students' attitude to clinical exposure and factors influencing their attitude towards clinical exposure, although a high proportion had a positive attitude, with high reported factors affecting their attitude. This could be because of the small sample size. The students' attitude to clinical exposure was statistically significant $(p=0.001)$, with average scores higher among level-500 students. This implies that a positive attitude to clinical exposure enhances students' behaviour during clinical training. Hence, the higher the level of study, the more positive the attitude towards clinical exposure. Intensive preparation of level-300 students for clinical training is important to improve their attitude towards clinical exposure.

\section{Conclusion}

Our findings indicate that students had a positive attitude towards clinical exposure. The identified factors did not significantly relate to their attitude towards such exposure. However, these factors may have an impact on their learning outcomes, such as bed making, taking vital signs, giving a bed bath, wound dressing, administration of medication and offering bed pans/ urinals. However, adequate clinical supervision and guidance are necessary for an effective clinical practice.

\section{Declaration. None.}

Acknowledgements. We thank the students of the Department of Nursing Science who consented to participate in the survey. We also thank Dr Wilbert Sibanda for the statistical input.

Author contributions. MIO contributed to the conception of the study, and drafted and revised the manuscript; BPN contributed to the revision of the manuscript; and ODM contributed to the conception of the study. All authors read and approved the final manuscript.

Funding. None.

Conflicts of interest. None.

\footnotetext{
1. Eta VEA, Atanga MBS, Atashii J, D'Cruz G. Nurses and challenges faced as clinical educators: A group of nurses in Cameroon. Pan Afr Med J 2011;8(2):467. https://doi.org/10.4314/pamj.v8i1.71085

. Ghodsbin F, Shafakhah M. Facilitating and preventing factors in learning clinical skills from the view points of the third year students of Fatemeh School of Nursing and Midwifery. Iran J Med Educ 2008;7(2):343-352.

3. Tiwaken SU, Caranto LC, David JT. The real world: Lived experiences of student nurses during clinical practice. Int J Nurs Sci 2015;5(2):66-75. https://doi.org/10.5923/j.nursing.20150502.05

4. Irby DM. Effective clinical teaching and learning: Clinical teaching and the clinical teacher. J Med Educ 1986;9(2):35-45.

5. Awuah-Peasah D, Sarfo LA, Asamoah F. The attitudes of student nurses toward clinical work. Int J Nurs Midwifery 2013;5(2):22-27. https://doi.org/10.5897/IJNM12.017

6. Dlama GJ, Modupe O, Umar A. Perception of nursing students and preceptors about factors influencing the clinical performance of nursing students. J Nurs Health Sci 2015;4(5):57-69.

Chan D. Development of an innovative tool to assess hospital learning. Nurse Educ Today 2009;21(8):624-63 https://doi.org/10.1054/nedt.2001.0595

. Chuan OL, Barnett T. Student tutor and staft perception of the clinical learning environment. Nurs Educ Prac 2012;12(8):192-197. https://doi.org/10.1016/j.nepr.2012.01.003

9. Sharif F, Masoumi S. A qualitative study of nursing student experiences of clinical practice. BMC Nurs 2005;4(6):1-7. https://doi.org/10.1186/1472-6955-4-6

10. Jack-Ide IO, Amiegheme FE, Ongutubor KE. Undergraduate nursing students' mental health and psychiatric clinical experience and their career choice in nursing: Perspectives from the Niger Delta Region of Nigeria. J Ment Disord Treat 2016;2(2):1-5. https://doi.org/10.4172/2471-271x.1000116

11. Papp I, Markkanen M, von Bonsdorff M. Clinical environment as a learning environment: Student nurses perceptions concerning clinical learning experiences. Nurse Educ Today 2003;23(4):262-268.

perceptions concerning clinical learning experiences. Nurse Educ Today 2003;23(4):262-268. environment: A research study. BMC Nurs 2016;15:44. https://doi.org/10.1186/s12912-016-0164-4

13. Elcigil A, Sari M. Determining problems experienced by student nurses in their work with clinical education in Turkey. Nurse Educ Today 2008;7:491-498. https://doi.org/10.5430/jnep.v4n11p82

14. Mabuda BT, Potgieter E, Alberts UU. Student nurses' experiences during clinical practice in the Limpopo 4. Mabuda BT, Potgieter E, Alberts UU. Student nurses' experiences during clinical
Province. Curationis 2008;31(1):19-27. https://doi.org/10.4102/curationis.v38i2.1517

5. Rajeswaran L. Clinical experiences of nursing students at a selected institute of health sciences in Botswana Health Sci J 2016;10(6):1-6. https://doi.org/10.21767/1791-809x.1000471

Health Sci J 2016;10(6):1-6. https://doi.org/10.21767/1791-809x.1000471
16. Buhat-Mendoza DG, Mendoza JNB, Tianela CT, Fabella EL. Correlation of academic and clinical performance of Libyan nursing student. J Nurs Educ Pract 2014;4(11):23-24. https://doi.org/10.5430/jnep.v4n11p82

17. Jamshidi N, Molazem Z, Sharif $F$, Torabizadeh C, Kalyani MN. The challenges of nursing students in the clinica learning environment: A qualitative study. Sci World J 2016:1-7. https://doi.org/10.1155/2016/1846178
} 